\title{
ARTICLE
}

\section{Evaluation of radiation levels and comparison with PHITS calculations for the BigRIPS separator in Radioactive Isotope Beam Factory}

\author{
Kanenobu Tanaka*, Naohito Inabe, Koichi Yoshida and Toshiyuki Kubo \\ RIKEN Nishina Center, 2-1 Hirosawa, Wako, Saitama, 351-0198, Japan
}

\begin{abstract}
Neutron radiation levels induced by intense beams of ${ }^{48} \mathrm{Ca},{ }^{124} \mathrm{Xe}$, and ${ }^{238} \mathrm{U}$ ions around the BigRIPS separator in the Radioactive Isotope Beam Factory (RIBF) were measured. The residual radioactivity of activated samples was also measured. The measured values agreed reasonably well with the results of calculations made by using PHITS simulation code.
\end{abstract}

Keywords: heavy ion beams; calcium-48 beam; xenon-124 beam; uranium-238 beam; in-flight radioactive isotope beam separator; neutron dose; residual radioactivity; activated sample; PHITS code

\section{Introduction}

The Radioactive Isotope Beam Factory (RIBF) facility was constructed to generate intense beams of a wide range of radioactive isotopes (RIs). The aim of the RIBF is to expand our knowledge of highly unstable exotic nuclei in relation to nuclear physics and nuclear astrophysics. The superconducting ring cyclotron, which is located at the end of the series of four cyclotrons, provides beams of heavy ions from hydrogen to uranium with an energy of about $350 \mathrm{MeV}$ per nucleon. The maximum intensity is expected to be as high as one particle microampere $\left(6.2 \times 10^{12}\right.$ particles/s $)$, which corresponds to a beam power of $80 \mathrm{~kW}$ in the case of ${ }^{238} \mathrm{U}[1]$. The primary beams are injected into the target of the BigRIPS superconducting separator. Intense RI beams are then produced by projectile fragmentation of the various heavy-ion beams or by in-flight fission of uranium ions. The produced RI beams are separated and identified at the BigRIPS separator, and subsequently transported to the experimental hall for use in various experiments [2]. Typically $10 \%$ of the primary beam interacts with the target and the remainder irradiates the beam dump of BigRIPS. Irradiation of the target and the beam dump by intense beams of heavy-ions induces nuclear reactions and generates high levels of radiation. It is therefore necessary to evaluate radiation levels, radiation heat loads, radiation damage, residual radioactivity, and other factors to ensure that it will be possible to deal with any problems associated with radiation.

In the design stage of BigRIPS, a simple formula was used to evaluate these radiation issues [3]. Recent progress in computing technology and simulation codes

*Corresponding author. Email: ktanaka@riken.jp permits more-precise evaluations to be made. In this study, we evaluated several aspects of the radiation associated with heavy-ion beams by means of physical measurements, and we compared our results with those of calculations made by using the Monte-Carlo Particle and Heavy-Ion Transport code System (PHITS) [4].

Because a variety of primary beams are used in BigRIPS, it is necessary to evaluate the radiation produced by several beam nuclides. Typical beam intensities, as of 2012 are 200 particle nanoamperes (pnA) for ${ }^{48} \mathrm{Ca}, 10 \mathrm{pnA}$ for ${ }^{124} \mathrm{Xe}$, and 1 pnA for ${ }^{238} \mathrm{U}$. ${ }^{48} \mathrm{Ca}$ is a neutron rich nucleus of a natural isotope that is useful in producing an extremely neutron-rich RI beam with projectile fragmentation. ${ }^{124} \mathrm{Xe}$ is a neutron-deficient nucleus that is useful in producing nuclei close to the proton drip-line. ${ }^{238} \mathrm{U}$ is used to produce a wide range of neutron-rich unstable nuclei of $Z>20$ through in-flight fission. To evaluate the radiation for the ${ }^{48} \mathrm{Ca}$ beam, the heat load on the first superconducting triplet quadrupole and the radioactivity of activated samples positioned around the beam dump of BigRIPS have been measured previously and the results have been compared with those of the corresponding PHITS calculations $[5,6]$. In the current study, neutron dose rates for ${ }^{48} \mathrm{Ca},{ }^{124} \mathrm{Xe}$ and ${ }^{238} \mathrm{U}$ beams, and the residual radioactivities of samples for ${ }^{124} \mathrm{Xe}$ and ${ }^{238} \mathrm{U}$ beams were measured and the results were compared with those of PHITS calculations.

\section{Experimental details and calculations}

\subsection{Neutron dose and shielding}

Neutron dose rates around BigRIPS were measured and the results were compared with those of PHITS calculations. Figure 1 shows the geometry of BigRIPS 
and the radiation shields for the PHITS calculations. The neutron radiation-shielding system of BigRIPS was designed by using a simple formula [3] in which the effective dose rate of neutrons in the shielding materials was assumed to depend on the angular distribution of the emitted neutrons and on their attenuation length. The angular distribution was determined empirically, and the attenuation length was deduced by using ANISN code [7]. The attenuation length was deduced under the assumption that the neutron energy is greater than 150 $\mathrm{MeV}$. The energy dependence and the streaming effect of the neutron flux were not taken into account. Therefore, we selected the positions for our measurements as points where large contributions from these effects were expected to occur.

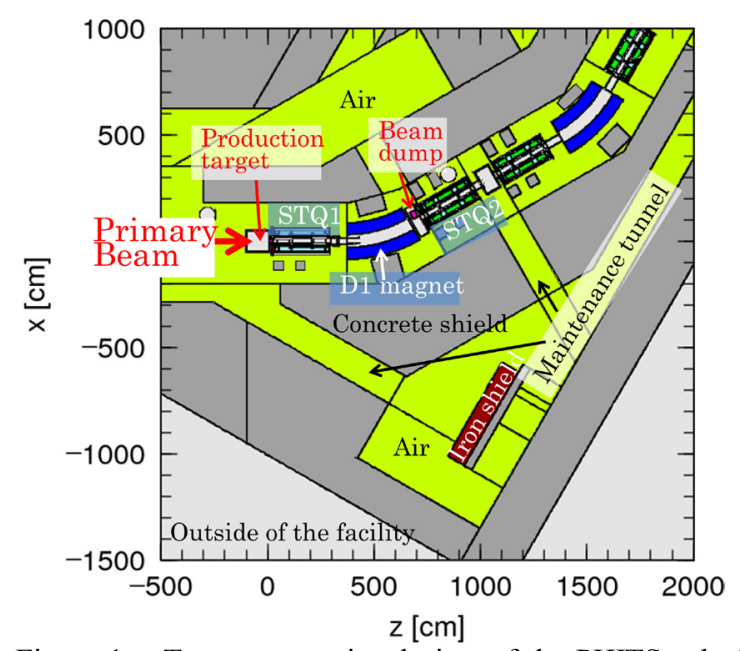

Figure 1. Top cross-sectional view of the PHITS calculation model of BigRIPS and radiation shield.

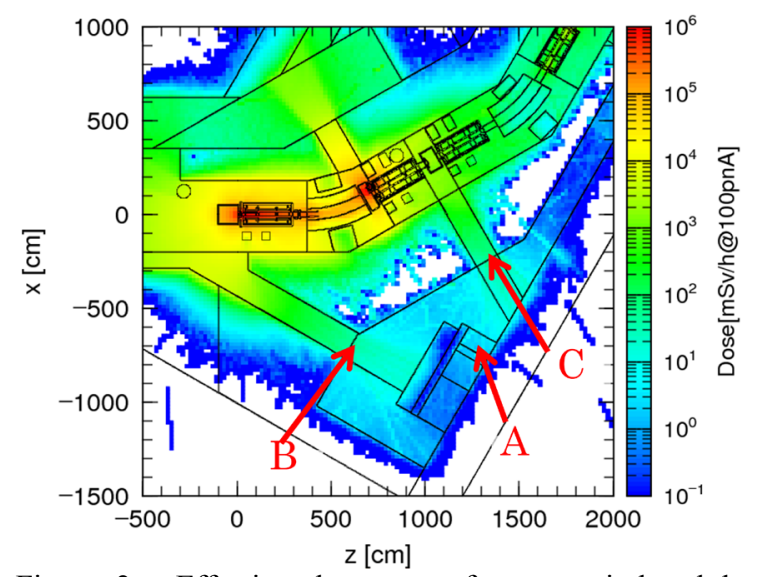

Figure 2. Effective dose rate of neutron induced by the intense ${ }^{48} \mathrm{Ca} 100 \mathrm{pnA}$ beam calculated by using PHITS. The conditions for the calculation are listed in Table 1. The positions for measurements of the neutron dose rate are also shown in the figure.

A TPC-451C neutron survey meter (ALOKA Co Ltd., Mitaka) was used for the measurements. The energy range was from $0.025 \mathrm{eV}$ to $15 \mathrm{MeV}$. Table 1 lists the measured dose rates at positions $\mathrm{A}-\mathrm{C}$, which are indicated in Figure 2. The dose ratio of calculation to measurement are also listed in the table 1 . The systematic error in the measurements was $20 \%$, arising from the inaccuracies in measuring the beam intensity. Figure 2 shows the neutron dose map calculated by using PHITS. In the code, nucleus-nucleus collisions are described by means of the JAERI Quantum Molecular Dynamics model, and the Generalized Evaporation Model is used to simulate the evaporation and fission processes of the excited states. Nucleon-nucleus collisions are described by means of the Jet AA Microscopic Transport Model [4]. The ENDF/B-VI library of evaluated nuclear data [8] is used to calculate neutron-induced reactions below $20 \mathrm{MeV}$.

Table 1. Measured neutron dose rate outside of the concrete shield for BigRIPS. The errors of measurement and calculation are taken into account in the dose-ratio errors.

\begin{tabular}{cccc}
\hline $\begin{array}{c}\text { Beam, Target, B } \rho 1 \\
(\mathrm{Tm})\end{array}$ & $\begin{array}{c}\text { Posi } \\
\text { tion }\end{array}$ & $\begin{array}{c}\text { Measured } \\
\text { dose rate } \\
(\mathrm{mSv} / \mathrm{h})\end{array}$ & $\begin{array}{c}\text { Dose ratio } \\
\text { (PHITS } \\
\text { /measurement) }\end{array}$ \\
\hline${ }^{48} \mathrm{Ca} 100 \mathrm{pnA}$, & $\mathrm{A}$ & 1.7 & $2.1 \pm 0.4$ \\
$\mathrm{Be} 15 \mathrm{~mm}, 8.200 \mathrm{Tm}$ & $\mathrm{B}$ & 27 & $1.9 \pm 0.4$ \\
& $\mathrm{C}$ & 25 & $2.0 \pm 0.4$ \\
${ }^{238} \mathrm{U} 1 \mathrm{pnA}$, & & & \\
$\mathrm{Be} 5 \mathrm{~mm}, 7.561 \mathrm{Tm}$ & $\mathrm{A}$ & 0.035 & $1.3 \pm 0.3$ \\
${ }^{124} \mathrm{Xe} \mathrm{10} \mathrm{pnA,}$ & $\mathrm{A}$ & 0.36 & $1.7 \pm 0.4$ \\
$\mathrm{Be} 4 \mathrm{~mm}, 5.255 \mathrm{Tm}$ & & & \\
\hline
\end{tabular}

The results listed in table 1 show that the PHITS calculations reproduce the measured results within factor of 2.5. Similar results have been reported by Satoh et al. who measured angler distributions of neutrons from several thick targets irradiated by heavy-ion beams [9]. The beam nuclides ranged from $\mathrm{He}$ to $\mathrm{Xe}$, with energies of 400-800 MeV/nucleon. The PHITS result for the produced neutrons agreed with the experimental ones within a factor of 3 [9]. The results of our current study therefore agrees with these results.

\subsection{Radiation sample}

The estimation of long-term residual radioactivity arising from irradiation by intense beams is important in relation to planning of strategies for the maintenance

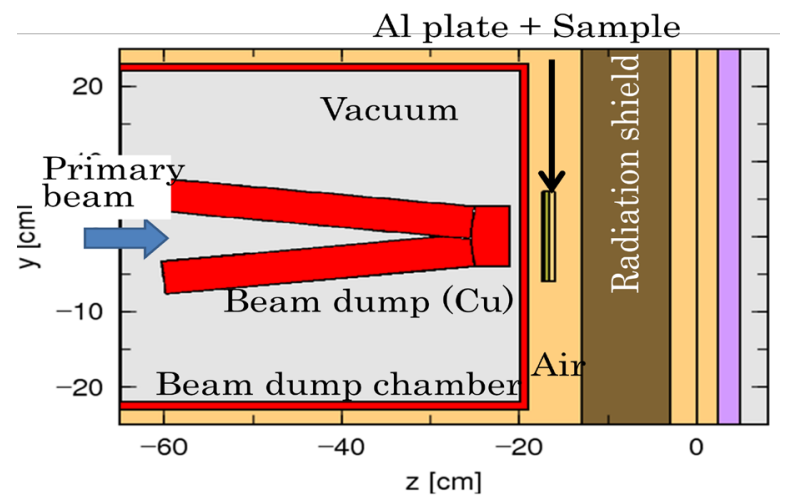

Figure 3. Side cross-sectional view of the experimental setup. Samples were installed between the beam dump chamber and a radiation shield. For more detail, see Ref. [6]. 
Table 2. Sizes of the samples placed in various directions forward of the beam dump. The angles are that between the direction of samples from the irradiation point on the beam dump and beam directions. The accuracy of the irradiation angle is $3^{\circ}$

\begin{tabular}{llrc}
\hline Material & Size (mm) & \multicolumn{2}{c}{ Angles (degree) } \\
& & ${ }^{238} \mathrm{U}$ & ${ }^{124} \mathrm{Xe}$ \\
\hline $\mathrm{Fe}$ & $10 \times 10 \times 1$ & 11 & 9 \\
$\mathrm{Ni}$ & $10 \times 10 \times 1$ & 8 & 7 \\
$\mathrm{Cr}$ & $10 \phi \times 5$ & 9 & 9 \\
$\mathrm{Cu}$ & $10 \times 10 \times 1$ & 7 & 6 \\
$\mathrm{Al}$ & $10 \times 10 \times 1$ & 11 & 10 \\
\hline
\end{tabular}

and improvement of BigRIPS. To estimate the future radioactivity at BigRIPS precisely, we examined the activation of samples experimentally to obtain benchmarks for PHITS calculations.

The residual radioactivity of irradiated samples located downstream of the beam dump was measured and the results were compared with those of PHITS calculations. Figure 3 shows the precise PHITS model of the experimental setup around the beam dump. The experimental method was the same as that in a previous study using a ${ }^{48} \mathrm{Ca}$ beam [6]. In the current study, ${ }^{124} \mathrm{Xe}$ and ${ }^{238} \mathrm{U}$ beams were used to activate the samples. The

Table 3. Radioactivity of the samples as ratios of PHITS-calculated results to the measured values (preliminary results) recorded 140 and 120 days after irradiation by the ${ }^{238} \mathrm{U}$ and the ${ }^{124} \mathrm{Xe}$ beam, respectively. Energies and half-lives of the nuclides are taken from the Table of Isotopes (Eight edition) [10]. Typical reactions and threshold energies used in the PHITS calculations are also shown in this table.

\begin{tabular}{|c|c|c|c|c|c|c|}
\hline \multirow{2}{*}{ Sample } & \multirow{2}{*}{ Nuclide } & \multirow{2}{*}{ Half life } & \multirow{2}{*}{ Energy (keV) } & \multicolumn{2}{|c|}{ PHITS/EXP } & \multirow{2}{*}{$\begin{array}{c}\text { Reaction / } \\
\text { threshold }(\mathrm{MeV})\end{array}$} \\
\hline & & & & ${ }^{238} \mathrm{U}$ & ${ }^{124} \mathrm{Xe}$ & \\
\hline $\begin{array}{c}\mathrm{Fe} \\
\left({ }^{54} \mathrm{Fe} 58^{8}\right.\end{array}$ & ${ }^{54} \mathrm{Mn}$ & $312.12 \mathrm{~d}$ & 835 & $1.25 \pm 0.46$ & $1.1 \pm 0.4$ & ${ }^{56} \mathrm{Fe}(\mathrm{n}, 2 \mathrm{n} \mathrm{p}){ }^{54} \mathrm{Mn} / 20.4$ \\
\hline $\begin{array}{l}{ }^{56} \mathrm{Fe} 91.7 \% \\
\mathrm{Fe} 2.2 \%\end{array}$ & ${ }^{46} \mathrm{Sc}$ & $83.79 \mathrm{~d}$ & 1121,889 & $0.89 \pm 0.38$ & $0.79 \pm 0.30$ & ${ }^{56} \mathrm{Fe}(\mathrm{n}, 4 \mathrm{n} 3 \mathrm{p} \alpha){ }^{46} \mathrm{Sc} / 67.4$ \\
\hline$\left.{ }^{58} \mathrm{Fe} 0.3 \%\right)$ & ${ }^{56} \mathrm{Co}$ & $77.27 \mathrm{~d}$ & $\begin{array}{l}847,1038,1238, \\
1771 \text { etc. }\end{array}$ & $0.90 \pm 0.50$ & $0.45 \pm 0.19$ & ${ }^{56} \mathrm{Fe}(\mathrm{p}, \mathrm{n}){ }^{56} \mathrm{Co} / 5.3$ \\
\hline \multirow{4}{*}{$\begin{array}{c}\mathrm{Ni} \\
\left({ }^{58} \mathrm{Ni} 67.8 \%\right. \\
{ }^{60} \mathrm{Ni} 26.2 \% \\
{ }^{61} \mathrm{Ni} 1.3 \% \\
{ }^{62} \mathrm{Ni} 3.7 \% \\
\left.{ }^{64} \mathrm{Ni} 1.2 \%\right)\end{array}$} & ${ }^{56} \mathrm{Co}$ & $77.27 \mathrm{~d}$ & $\begin{array}{l}847,1038,1238, \\
1771 \text { etc. }\end{array}$ & $1.7 \pm 0.5$ & $2.0 \pm 0.7$ & ${ }^{58} \mathrm{Ni}(\mathrm{n}, 2 \mathrm{n} \mathrm{p}){ }^{56} \mathrm{Co} / 19.5$ \\
\hline & ${ }^{58} \mathrm{Co}$ & $70.82 \mathrm{~d}$ & 811 & $0.96 \pm 0.27$ & $1.2 \pm 0.4$ & ${ }^{58} \mathrm{Ni}(\mathrm{n}, \mathrm{p}){ }^{58} \mathrm{Co} /-0.4$ \\
\hline & ${ }^{54} \mathrm{Mn}$ & $312.12 d$ & 835 & $0.95 \pm 0.28$ & $1.1 \pm 0.4$ & ${ }^{58} \mathrm{Ni}(\mathrm{n}, 2 \mathrm{n} 3 \mathrm{p}){ }^{54} \mathrm{Mn} / 34.6$ \\
\hline & ${ }^{60} \mathrm{Co}$ & $5.27 \mathrm{y}$ & 1173,1333 & $0.78 \pm 0.31$ & $1.2 \pm 0.5$ & ${ }^{60} \mathrm{Ni}(\mathrm{n}, \mathrm{p}){ }^{60} \mathrm{Co} / 2.0$ \\
\hline $\begin{array}{c}\mathrm{Cr} \\
{ }^{50} \mathrm{Cr} 4.3 \% \\
{ }^{52} \mathrm{Cr} 83.8 \% \\
{ }^{53} \mathrm{Cr} 9.6 \% \\
\left.{ }^{54} \mathrm{Cr} 2.4 \%\right)\end{array}$ & ${ }^{46} \mathrm{Sc}$ & $83.79 d$ & 1121,889 & $1.1 \pm 0.4$ & $1.4 \pm 0.5$ & $\begin{array}{l}{ }^{52} \mathrm{Cr}(\mathrm{n}, 4 \mathrm{n} 3 \mathrm{p}){ }^{46} \mathrm{Sc} / 59.7 \\
{ }^{52} \mathrm{Cr}(\mathrm{n}, 2 \mathrm{n} \mathrm{p} \mathrm{\alpha})^{46} \mathrm{Sc} / 31.4 \\
{ }^{52} \mathrm{Cr}(\mathrm{n}, 3 \mathrm{n} 2 \mathrm{p} \mathrm{d}){ }^{46} \mathrm{Sc} / 57.5\end{array}$ \\
\hline $\begin{array}{c}\mathrm{Al} \\
\left({ }^{27} \mathrm{Al} 100 \%\right)\end{array}$ & ${ }^{22} \mathrm{Na}$ & $2.6 y$ & 1275 & $4.0 \pm 2.3$ & $1.1 \pm 0.4$ & ${ }^{27} \mathrm{Al}(\mathrm{n}, 4 \mathrm{n} 2 \mathrm{p}){ }^{22} \mathrm{Na} / 50.8$ \\
\hline \multirow[t]{4}{*}{$\begin{array}{c}\mathrm{Cu} \\
\left({ }^{63} \mathrm{Cu} \mathrm{69.1 \%}\right. \\
{ }^{65} \mathrm{Cu} \mathrm{30.9 \% )}\end{array}$} & ${ }^{58} \mathrm{Co}$ & $70.82 d$ & 811 & $0.79 \pm 0.29$ & $0.80 \pm 0.29$ & $\begin{array}{l}{ }^{63} \mathrm{Cu}(\mathrm{n}, 4 \mathrm{n} 2 \mathrm{p}){ }^{58} \mathrm{Co} / 44.5 \\
{ }^{63} \mathrm{Cu}(\mathrm{n}, 2 \mathrm{n} \alpha){ }^{58} \mathrm{Co} / 16.2 \\
{ }^{65} \mathrm{Cu}(\mathrm{n}, 6 \mathrm{n} 2 \mathrm{p}){ }^{58} \mathrm{Co} / 62.4 \\
{ }^{65} \mathrm{Cu}(\mathrm{n}, 4 \mathrm{n} \alpha){ }^{58} \mathrm{Co} / 34.1\end{array}$ \\
\hline & ${ }^{56} \mathrm{Co}$ & $77.27 \mathrm{~d}$ & $\begin{array}{l}847,1038,1238, \\
1771 \text { etc. }\end{array}$ & $0.76 \pm 0.30$ & $0.68 \pm 0.26$ & $\begin{array}{l}{ }^{63} \mathrm{Cu}(\mathrm{n}, 6 \mathrm{n} 2 \mathrm{p}){ }^{56} \mathrm{Co} / 64.5 \\
{ }^{63} \mathrm{Cu}(\mathrm{n}, 4 \mathrm{n} \alpha)^{56} \mathrm{Co} / 36.2\end{array}$ \\
\hline & ${ }^{54} \mathrm{Mn}$ & $312.12 d$ & 835 & $1.0 \pm 0.4$ & $0.97 \pm 0.36$ & $\begin{array}{l}{ }^{63} \mathrm{Cu}(\mathrm{n}, 4 \mathrm{n} 2 \mathrm{p} \alpha){ }^{54} \mathrm{Mn} / 51.2 \\
{ }^{63} \mathrm{Cu}(\mathrm{n}, 6 \mathrm{n} 4 \mathrm{p}){ }^{54} \mathrm{Mn} / 79.5\end{array}$ \\
\hline & ${ }^{60} \mathrm{Co}$ & $5.27 \mathrm{y}$ & 1173,1333 & $1.2 \pm 0.5$ & $1.2 \pm 0.5$ & $\begin{array}{l}{ }^{63} \mathrm{Cu}(\mathrm{n}, 2 \mathrm{n} 2 \mathrm{p}){ }^{60} \mathrm{Co} / 26.6 \\
{ }^{65} \mathrm{Cu}(\mathrm{n}, 4 \mathrm{n} 2 \mathrm{p}){ }^{60} \mathrm{Co} / 44.4\end{array}$ \\
\hline
\end{tabular}


primary beam at $345 \mathrm{MeV} /$ nucleon was injected into the copper beam dump. The primary beam and most of the charged particles generated by the nuclear reaction at the beam dump were stopped in the beam dump. Thus, the particles that irradiated and activated the samples were mainly secondary neutrons. Table $\mathbf{2}$ shows the properties of the sample materials. The elements which present in the samples were those widely used in the fabrication of vacuum chambers, magnets, and other components of BigRIPS. The irradiation dose at the beam dump was $3.2 \times 10^{13}(1.5 \mathrm{pnA}, \sim 1 \mathrm{~h})$ for ${ }^{238} \mathrm{U}$ ions and $1.8 \times 10^{14}(8 \mathrm{pnA}, \sim 1 \mathrm{~h})$ for ${ }^{124} \mathrm{Xe}$ ions.

The $\gamma$-ray spectra of the samples were recorded by using a GC2019 Ge detector (Canberra Co. Ltd. Meriden, USA). For the purpose of estimating the long-term radioactivity, the $\gamma$-ray spectra from the activated samples were measured after about 140 and 120 days of cooling time for ${ }^{238} \mathrm{U}$ and ${ }^{124} \mathrm{Xe}$, respectively; these intervals were sufficient to eliminate short-lived radioactivity. The rates of production of the radioactive nuclei were deduced from the peak areas of the $\gamma$-ray spectra, the efficiency of the Ge detector and the half-lives of the nuclei. The error in the production rate took into account the statistical errors in the net-peak area, errors in the efficiency of the Ge detector, uncertainties in the beam-irradiation dose, and the accuracy of the sample positions. Table 3 shows the preliminary results of activation in terms of ratios of the values obtained by PHITS calculations to those obtained by measurements. Only long-lived major radioactive nuclides among the observed nuclei are listed in the table.

The calculated radioactivities of samples irradiated with ${ }^{238} \mathrm{U}$ and ${ }^{124} \mathrm{Xe}$ were close to the measured values, except in a few cases. A similar tendency has been observed with the ${ }^{48} \mathrm{Ca}$ beam [6]. Niita et al. calculated the production cross section of nuclei in heavy-ion collisions in a thick $\mathrm{Cu}$ target by using PHITS, and they compared their results with measured values [11]. The beam nuclides in this case were $\mathrm{Ar}, \mathrm{C}, \mathrm{Ne}$, and $\mathrm{Si}$, at several hundreds of $\mathrm{MeV} /$ nucleon of energy. In general, their calculated results agreed with their experimental values within a factor of 2 [11]. Our present results for ${ }^{238} \mathrm{U}$ and ${ }^{124} \mathrm{Xe}$, which are heavier nuclides than those used in the evaluation made by Niita et al., agree well with their results.

\section{Summary}

Neutron dose rates outside the radiation shield were measured for irradiation with ${ }^{48} \mathrm{Ca},{ }^{124} \mathrm{Xe}$ and ${ }^{238} \mathrm{U}$ beams at the target and the beam dump of BigRIPS. The residual radioactivities induced in several samples located near the beam dump were also measured. The samples were activated with secondary neutrons generated by the ${ }^{124} \mathrm{Xe}$ and ${ }^{238} \mathrm{U}$ beam at the beam dump. When the measured results of the neutron doses and the radioactivities of the samples were compared with those calculated by PHITS, they agreed within a factor of 2.5.

\section{Acknowledgements}

The PHITS calculations were performed using RIKEN Integrated Cluster of Clusters (RICC) facility, which allows fast and large scale computations. We thank RIKEN for supporting the computing facilities which are essential for the completion of the work.

\section{References}

[1] Y. Yano, The RIKEN RI beam factory project: A status report, Nucl. Instr. Meth. Phys. Res., Sect. B261 (2007), pp. 1009-1013.

[2] T. Kubo, In-flight RI beam separator BigRIPS at RIKEN and elsewhere in Japan, Nucl. Instr. Meth. Phys. Res., Sect. B204 (2003), pp. 97-113.

[3] N. Fukunishi, S. Ito, Y. Uwamino and Y. Yano, Shielding design of RIKEN RI beam factory, Proc. 12th Symp. on Accelerator Science and Technology, Oct. 27-29, 1999, Wako, Japan, (1999).

[4] K. Niita, N. Matsuda, Y. Iwamoto, H. Iwase, T. Sato, H. Nakashima, Y. Sakamoto and L. Sihver, PHITS: Particle and Heavy Ion Transport Code System, Version 2.23, JAEA-Data/Code 2010-022, Japan Atomic Energy Agency, (2010).

[5] T. Ohnishi, K. Kusaka and T. Kubo, Radiation transport calculation using PHITS code for radiation heat load and damage to superconducting radioactive isotope beam separator BigRIPS at RIKEN, Prog. Nucl. Sci. Technol. 2 (2011), pp. 416-420.

[6] K. Tanaka, N. Inabe, T. Ohnishi and T. Kubo, Radiation transport calculation using PHITS code for the activation of BigRIPS separator at RIKEN Radioactive Isotope Beam Factory and comparison with the measurement, Prog. Nucl. Sci. Technol. 2 (2011), pp. 955-959.

[7] W. W. Engle, Jr., A user's manual for ANISN, a one dimensional discrete ordinates transport cose with anisotropic scattering, K-1963, Oak Ridge gaseous diffusion plant, Oak Ridge (1967).

[8] V. McLane and members of the cross section evaluation working group, ENDF/B-VI summary documentation. BNL-NCS-17541, (1996).

[9] D. Satoh, K. Kurosawa, T. Sato, A. Endo, M. Takada, H. Iwase, T. Nakamura and K. Niita, Reevaluation of secondary neutron spectra from thick targets upon heavy-ion bombardment, Nucl. Instr. Meth. Phys. Res., Sect. A583 (2007), pp. 507-515.

[10]R. B. Firstone, C. M. Bglin, S. F. Y. Chu (Eds.), Table of Isotopes (8th ed.), John Wiley \& Sons, New York (1996).

[11]K. Niita, T. Sato, H. Iwase, H. Nose, H. Nakashima, L. Shiber, PHITS: a particle and heavy ion transport code system, Radiat. Meas, 41 (2006), pp. 1080-1090. 